\title{
Factors Related to Self-Confidence to Live Alone in Community-Dwelling Older Adults: A Cross-Sectional Study
}

So Im Ryu', BeLong Cho ${ }^{2,3}$, Sun Ju Chang ${ }^{1,4}$, Hana Ko ${ }^{5}$, Yu Mi Yi ${ }^{6}$, Eun-Young Noh ${ }^{1}$, Hye Ryung Cho ${ }^{4}$ and Yeon-Hwan Park ${ }^{1,4^{*}}$

\begin{abstract}
Background: Many older adults prefer to live alone in their own homes, with age-related issues in physical movement, regardless of their cultural background. Importantly, however, to identify the features of successfully ageing in place (AIP), and foster independent living among these individuals, this study explored their level of selfconfidence to live alone and its related factors.

Methods: We conducted a cross-sectional study using secondary data from an earlier study with older adults living alone in South Korea recruited by convenience sampling methods ( $N=936$, mean age $=77.1$ years, $76.1 \%$ female). Data regarding the general, health-related, and social characteristics as well as self-confidence to live alone were collected via face-to-face interviews in 2019. Self-confidence to live alone was measured with a numeric rating scale of 0 to 10 .

Results: The average self-confidence score to live alone was 6.59. A regression analysis showed that mould exposure at home, depression, emergency department visits, and loneliness hinder self-confidence to live alone. Meanwhile, such self-confidence was facilitated by independency in instrumental activities of daily living (IADL), interactions with family members, social service utilisation, and social support.

Conclusions: This study suggests that healthcare providers need to consider the importance of self-confidence to live alone and influencing functional, mental, social, and environmental factors to promote quality of life as well as successful AIP for older adults living alone. Further, self-confidence to live alone could be a new practical index in the field of health and ageing to screen the successful AIP of older adults living alone.
\end{abstract}

Keywords: Ageing, Independent living, Self-concept, Social isolation, Depression, Safety

\footnotetext{
* Correspondence: hanipyh@snu.ac.kr

${ }^{1}$ College of Nursing, The Research Institute of Nursing Science, Seoul

National University, Seoul, 103, Daehak-ro, Jongno-gu, Seoul 03080, Republic

of Korea

${ }^{4}$ College of Nursing, Seoul National University, Seoul, 103, Daehak-ro,

Jongno-gu, Seoul 03080, Republic of Korea

Full list of author information is available at the end of the article
}

(c) The Author(s). 2021 Open Access This article is licensed under a Creative Commons Attribution 4.0 International License, which permits use, sharing, adaptation, distribution and reproduction in any medium or format, as long as you give appropriate credit to the original author(s) and the source, provide a link to the Creative Commons licence, and indicate if changes were made. The images or other third party material in this article are included in the article's Creative Commons licence, unless indicated otherwise in a credit line to the material. If material is not included in the article's Creative Commons licence and your intended use is not permitted by statutory regulation or exceeds the permitted use, you will need to obtain permission directly from the copyright holder. To view a copy of this licence, visit http://creativecommons.org/licenses/by/4.0/ The Creative Commons Public Domain Dedication waiver (http://creativecommons.org/publicdomain/zero/1.0/) applies to the data made available in this article, unless otherwise stated in a credit line to the data. 


\section{Background}

The number of older adults living alone has risen and is expected to increase, particularly in Western and developed countries, including South Korea [1, 2]. Notably, these individuals are a vulnerable group that can face serious challenges to successfully ageing in place (AIP) because they tend to be socially isolated, feel lonelier [3], have poor health status [4], and lower life satisfaction [5]. Nevertheless, a majority of them strongly prefer to live in their own home, even in cases of age-related issues in physical movement, regardless of their cultural background $[6,7]$.

AIP has emerged as a key concept in the field of gerontology, reflecting an increase in the ageing population, and their living preferences [8]. It is defined as 'meeting the desire and ability of people, through the provision of appropriate services and assistance, to remain living relatively independently in the community in his or her current home or an appropriate level of housing' [9]. As many researchers have asserted a positive impact on self-identity, autonomy, and well-being, AIP has become an important strategy to overcome the challenges that we encounter $[10,11]$. However, recent studies have pointed out that all stakeholders need to be alert about the 'stuck-in-place' issues that accompany living with a shortage of financial, physical, and social resources necessary to live independently [12].

For older adults living in the community, independent living means to live in their own homes with a sense of control and freedom of decision and movement [13]. Sense of control has been considered a 'status' goal in many studies [14]. However, as successful AIP is an eventual process of balancing and adapting to both personal and environmental changes in the way of ageing [15], previous concepts such as sense of control are limited to reflecting dynamic interactions between a person and their environment. A previous qualitative study focussing on the concept of AIP emphasised that it is a process rather than a constant state, and studied the perception of one's ability as a feature of a successful AIP [16]. In addition, previous qualitative studies have demonstrated that a salient attribute of a person ageing successfully is their faith and trust to live independently and adapting to any circumstances even with physical discomfort; this can be defined as self-confidence [17-19]. Therefore, successful AIP can be considered as ageing with confidence in one's ability to live independently with a sense of control [17]. However, self-confidence to live alone, as a pioneering concept for AIP, has not yet been explored. Thus, we need to comprehensively examine the factors that influence this, along with the accumulated knowledge of factors for AIP and independent living.

According to previous studies, regarding demographic characteristics, women and old people ( $\geq 75$ years old) are less likely to AIP [17], while having religion, a higher income, independent earning, higher educational level, and satisfaction with the condition of housing, facilitates AIP $[6,20]$. Many previous studies related to residential spaces have been concerned with 'age-friendly modification' such as basic housing facilities [21]. In fact, the World Health Organization [22] reported the prevalence of indoor dampness estimated at 10-50\% worldwide. In addition, $20-30 \%$ of the older adults who were at risk of poverty in Europe, reported experiencing leaky roofs, dampness, and broken windows or rotten frames, as was the case in South Korea [23, 24]. Thus, it is necessary to explore the effect of mould exposure and wall cracks at home on individuals' self-confidence to live alone.

Daily living difficulties like health-related characteristics, disabilities, and other instrumental activities hinder independence negatively and affect independent living and AIP $[25,26]$. In addition, those with more chronic conditions and depressive symptoms are less likely to live independently $[6,26]$. According to a qualitative study that explored the experience of AIP by interviewing older women with physical discomfort living alone, 'falling' was one of the biggest challenges they faced in daily living [19]. Due to a decline in physical, sensory, and cognitive functions, older adults experience the highest risk of fall-related deaths or severe injuries [27], and approximately $33.7 \%$ injured by falls, visit the emergency department (ED) [28]. In particular, older adults who live alone experience helplessness because there is no one to help them in the event of a fall, which leads to feelings of fear and lack of safety [29]. Despite the emphasis on health-related safety for AIP, it has rarely been addressed to the best of our knowledge [30].

Concerning social characteristics, participation in social activities [19, 21]; interaction with friends, neighbours, and family [21]; and social support, positively affects AIP [17]. However, loneliness affects AIP negatively in older adults [17]. Even though the importance of community-based services has been emphasised [10], a longitudinal study demonstrated that older adults who used community-based services were less likely to age in place [6]. Thus, the effect of public service on older adults living alone needs to be further explored.

Inferring from previous studies, some general characteristics (religion, income, educational level, condition of house, participation in economic activity), social networks, and social support can promote self-confidence to live alone, whereas other general characteristics (female, old age), decreased function (disability, IADL), physical condition (number of comorbidities), mental health (depressive symptoms), and loneliness can hinder it. Further exploration is needed with regard to wall cracks and mould exposure at home, falls, ED visits, and public service utilisation. 
Therefore, it is necessary to identify the factors influencing the self-confidence to live alone, comprehensively, with respect to general, health-related, and social characteristics.

\section{Purpose}

This study aimed to explore the extent of selfconfidence to live alone and related factors in older adults living alone.

\section{Methods \\ Design}

This is a cross-sectional study using secondary data from a project funded by the Ministry of Health \& Welfare, Republic of Korea (Grant number: HI18C1284). The project aimed to identify service needs and develop a community-based integrated service for older adults living alone.

\section{Participants}

The participants of this study were South Korean older adults living alone in $\mathrm{S}^{*}$ city who participated in the original project's second-year cohort study. Among the participants $(n=1041)$ in the original study, a total of 936 participants (aged 67-96 years) without severe cognitive impairment (MMSE $\leq 17$ ), who could be evaluated for the ability of instrumental activity of daily living, and had no acute mobility problems due to facture (including arthrosis or spondylopathy) or severe disease surgery within the two months prior to the study, were chosen as the sample for this study.

Power analysis was conducted using the G*power 3.1 programme. To identify factors influencing the selfconfidence to live alone, effect size was calculated using linear multiple regression $\left(\alpha=.05, \beta=.05\right.$, effect size $f^{2}=$ $.06)$, as described in a previous study $\left(\operatorname{Adj-R^{2}}=.41\right)$ [26]. To secure power, at least 546 participants were needed under these conditions. Therefore, this study satisfied the minimum number of participants to secure power.

\section{Measurements \\ General characteristics}

Age, sex, educational level, religion, personal income, participation in economic activity, wall cracks, and mould exposure at home, were evaluated to assess the participants' general characteristics. While age and personal income were measured as continuous variables, sex, educational level, religion, participation in economic activity, wall cracks, and mould exposure at home were measured as categorical variables. Personal income was categorised based on the average income of older adults in Korea $(980,000 \mathrm{KRW} /$ month) in 2017 [7].

\section{Health-related characteristics}

To assess the health-related characteristics of the participants, functional, physical and mental health, fall history, and ED visits were evaluated.

Functional health Disability was checked as a binomial variable (yes/no) based on whether it was diagnosed and registered in the government grading system. Instrumental activities of daily living were evaluated with the Korean Instrumental Activities of Daily Living (K-IADL) Scale, which has been widely used in Korea [31]. The KIADL comprises 10 items for evaluating older adults' functions, such as grooming, housework, and preparing meals. All items are self-reported on a 3-point Likert scale with the following options: independent, partially dependent, and dependent. The total score ranges from 10 to 30, with higher scores indicating greater independence in instrumental activities of daily living. Respondents were categorised into the three groups: independent (all answers independent), partially dependent (at least one answer partially dependent), and dependent (at least one answer dependent) based on their report [32]. The Cronbach's alpha value was .94 in the validity-identifying study [33]; in the current study, it was .81 .

Physical health The number of comorbidities as a continuous variable was counted against a specific list of diseases. The list was compiled based on the '2017 survey of living conditions and welfare needs of Korean older persons' [7] and modified by the authors to include some additional diseases.

Mental health The Korean version [34] of the Geriatric Depression Scale Short Form [35] was used to evaluate depressive symptoms. This is a 15 -item scale, and all items are self-reported as binomial variables (yes/no); total scores range from 0 to 15 , with higher scores indicating more depressive symptoms. The scores are classified into the following categories: normal $(\leq 4)$, depression $(\geq 5)$. In both the Korean versions of the scale [34] and in the current study, Cronbach's alpha was .88 .

Falls Falls were measured as an ordinal variable using a single question: 'How many times have you fallen in the last year? (i.e. coming to fall on the ground or floor or other lower level)' [27].

ED visits ED visits were measured as an ordinal variable with a single question: 'How many times have you visited the ED in the last year?' 


\section{Social characteristics}

Social network The social network measured the frequency of participation in social activities, and interactions with family members and neighbours (friends) by referring to the 'Survey on the current status of older adults living alone', which is used to select targets for 'Care services for older Koreans' [36]. When analysed, these were converted to binary variables based on previous studies. Social interactions and interactions with family and neighbours (friends) were categorised against the baseline of three times a week [37] and monthly contact, respectively [38].

Public service utilisation The utilisation of public services was identified based on the items of the 'Survey on the current status of older adults living alone' [31] by adding and modifying some items frequently used by older adults living alone in Korea (e.g. basic or comprehensive care services for older Koreans).

Social support Enhancing Recovery in Coronary Health Disease (ENRICHD) Social Support Instrument (ESSI) [39], which was translated into Korean, was used [40]. This 6-item instrument was self-reported as a binomial variable (yes/no). Total scores range from 0 to 6 , with higher scores indicating higher social support. Scores can be classified into three categories: good score $=6$, fair score $=4$ to 5 , and poor score $\leq 3$. Cronbach's alpha of the Korean version of the scale was .84; in the current study, it was .78.

Loneliness The Korean version [41] of the revised UCLA Loneliness Scale [42] was used to evaluate the level of loneliness. The scale comprises 20 self-reported items with a 4 -point Likert scale $(1=$ never to $4=$ often $)$. Total scores range from 20 to 80 , with higher scores indicating greater loneliness. Scores can be classified into four categories: low $(\leq 34)$, moderate (35 to 49 ), moderately high (50 to 64), high ( $\geq 65$ ) [43]. Cronbach's alpha values for the Korean version of the scale and the current study were .93 and .91 , respectively.

\section{Self-confidence to live alone}

Self-confidence to live alone was measured using a single question: 'What is your current level of self-confidence to live alone?' Participants responded with a numeric rating scale (NRS) from 0 for 'no confidence' to 10 for 'very confident'.

\section{Data collection}

The original data were collected through face-to-face interviews by trained research assistants from August 12 to 23, 2019 at health or welfare centres in S* City, South
Korea. All research assistants were trained in the objectives, research tools, data collection methods, instructions for questionnaires, and ethical considerations of the study for $2 \mathrm{~h}$ or more. The researchers received coded data, which were used for secondary data analysis.

\section{Data analysis}

All statistical analyses were performed using the SPSS version 22 (IBM Corp., Armonk, N.Y., USA) with $p<.05$ as the significance level. Participants' self-confidence in living alone and all characteristics including general, health, social, and health-related safety were analysed using descriptive statistics (e.g. means, standard deviations, numbers, percentiles, ranges). To determine the differences in self-confidence and the relationship between participant characteristics, independent $t$-tests and Pearson's correlation coefficients were used for categorical and continuous variables, respectively. To evaluate the predictors of self-confidence to live alone, hierarchical multiple linear regression analyses were performed. We chose predictors with $p<.05$ in the bivariate analyses for the regression model.

\section{Results \\ Participants' self-confidence to live alone and general characteristics}

Among the 936 participants, the average score on selfconfidence to live alone was 6.59 on the scale from 0 to 10 (Table 1). The mean age was 77.1 years, $76.1 \%$ were female, and more than half of the participants (68.1\%) had an educational level below elementary school and followed a religion (66.3\%). The participants' average personal income was approximately 613,000 KRW, mostly lower than $980,000 \mathrm{KRW}$, which is the average income of older adults in South Korea. Further, $65.9 \%$ of the participants were not involved in economic activity, $20.4 \%$ had cracks in the walls, and $29.8 \%$ had mould in the house.

\section{Participants' health-related and social characteristics}

Table 2 shows the health-related and social characteristics of the participants. A total of $20 \%$ of the participants had disabilities, and $81.4 \%$ performed IADL independently. Most participants (95.6\%) had one or more diseases with an average of approximately four diseases in total, and more than half of the participants had depressive symptoms. Additionally, $26.1 \%$ of the participants reported experiencing one or more falls, of which $5.7 \%$ experienced three or more falls. Approximately $11.2 \%$ of the participants had visited the ED within the last year, and approximately $1 \%$ reported that they had visited the ED more than three times.

Regarding social characteristics, $73.3 \%$ participated in social activities, and $45.4 \%$ actively participated three to 
Table 1 Self-confidence to live alone and general characteristics of participants $(N=936)$

\begin{tabular}{|c|c|c|c|c|}
\hline Variables & Categories & $n(\%)$ & Mean $\pm S D$ & Range \\
\hline Self-confidence to live alone & & & $6.59 \pm 3.01$ & $0-10$ \\
\hline \multicolumn{5}{|l|}{ General characteristics } \\
\hline \multirow[t]{3}{*}{ Age (years) } & $65-74$ & $315(33.7)$ & $77.1 \pm 5.44$ & $67-96$ \\
\hline & $75-84$ & $533(56.9)$ & & \\
\hline & $\geq 85$ & $88(9.4)$ & & \\
\hline \multirow[t]{2}{*}{ Sex } & Male & $224(23.9)$ & & \\
\hline & Female & $712(76.1)$ & & \\
\hline \multirow[t]{5}{*}{ Educational level } & Uneducated & $333(35.6)$ & & \\
\hline & Elementary school & $304(32.5)$ & & \\
\hline & Middle school & $143(15.3)$ & & \\
\hline & High school & $121(12.9)$ & & \\
\hline & $\geq$ College & $35(3.7)$ & & \\
\hline \multirow[t]{2}{*}{ Religion } & Yes & $621(66.3)$ & & \\
\hline & No & $315(33.7)$ & & \\
\hline \multirow[t]{2}{*}{ Personal income } & $<980,000 \mathrm{KRW} /$ month & $837(89.4)$ & $612,511 \pm 398,021$ & $0-6,000,000$ \\
\hline & $\geq 980,000 \mathrm{KRW} /$ month & 99 (10.6) & & \\
\hline \multirow[t]{4}{*}{ Participation in economic activity } & $\geq 3-4$ times/week & $241(25.7)$ & & \\
\hline & $\geq 1-2$ times/week & $73(7.8)$ & & \\
\hline & $\geq 1-2$ times/month & $5(0.5)$ & & \\
\hline & None & $617(65.9)$ & & \\
\hline \multirow[t]{2}{*}{ Wall cracks at home } & Yes & $191(20.4)$ & & \\
\hline & No & $745(79.6)$ & & \\
\hline \multirow[t]{2}{*}{ Mould exposure at home } & Yes & $279(29.8)$ & & \\
\hline & No & 657 (70.2) & & \\
\hline
\end{tabular}

SD Standard deviation, IADL Instrumental activities of daily living, KRW Korean Won

four times a week. Approximately $88 \%$ of the participants were intercommunicating with family or neighbours more than once or twice a year. In particular, the rates of active communication with family members and neighbours at least once a week were 46.9 and $74.6 \%$, respectively. Approximately $45.2 \%$ received public services, $41.1 \%$ lacked social support, and $64.3 \%$ felt moderate to high loneliness.

\section{Factors affecting self-confidence to live alone}

Categorical and continuous variables were analysed to identify the relationship between self-confidence to live alone and each of the variables, without controlling for covariates (Tables 3 and 4). As shown in Table 3, in terms of general characteristics, participants with a highlevel educational background, economically active participants, and participants who were not exposed to wall cracks or mould at home had higher confidence in living alone than their counterparts. Regarding health-related characteristics, IADL-independent and non-depressed participants showed more self-confidence in living alone. In addition, participants who were involved in social activities, who communicated with their family members or neighbours, who did not receive public services, who had high social support, and who felt less loneliness showed more confidence in living alone. Among the continuous variables, income showed a positive correlation with self-confidence to live alone, but the number of comorbidities, fall history, and ED visits were negatively correlated with self-confidence to live alone (Table 4).

For the regression model, variables with significance levels $<.05$ in Tables 3 and 4 were selected. The variance inflation factor (VIF) ranged from 1.032 to 1.636 in all models, and the Durbin-Watson statistic was 1.960 for Model 3. Thus, it is supposed that there were no intercorrelations between variables (i.e. VIF <

10) and no statistical evidence of autocorrelation was found (i.e. $1.8<\mathrm{d}<2.2$ ) [44]. The results of the hierarchical multiple linear regressions are presented in Table 5. Each stage tested the relationship between self-confidence to live alone and the participants' characteristics step-by-step. All models were significant $(p<.05)$; the adjusted $R^{2}$ value increased from 
Table 2 Health-related and social characteristics of participants $(N=936)$

\begin{tabular}{|c|c|c|c|c|}
\hline Variables & Categories & $n(\%)$ & Mean $\pm S D$ & Range \\
\hline \multicolumn{5}{|l|}{ Health-related characteristics } \\
\hline \multirow[t]{2}{*}{ Disability } & Yes & $187(20.0)$ & & \\
\hline & No & $749(80.0)$ & & \\
\hline \multirow[t]{3}{*}{ IADL } & Independent & $762(81.4)$ & $10.49 \pm 1.54$ & $10-24$ \\
\hline & Partially dependent & $148(15.8)$ & & \\
\hline & Dependent & $26(2.8)$ & & \\
\hline \multirow[t]{2}{*}{ Number of comorbidities } & None & $41(4.4)$ & $3.94 \pm 2.38$ & $0-12$ \\
\hline & $\geq 1$ & $895(95.6)$ & & \\
\hline \multirow[t]{2}{*}{ Depression } & Normal & $414(44.3)$ & $5.89 \pm 4.30$ & $0-15$ \\
\hline & Depression & $522(55.7)$ & & \\
\hline \multirow[t]{4}{*}{ Falls (times/year) } & None & $692(73.9)$ & $0.52 \pm 1.40$ & $0-20$ \\
\hline & 1 & $142(15.2)$ & & \\
\hline & 2 & $48(5.2)$ & & \\
\hline & $\geq 3$ & $54(5.7)$ & & \\
\hline \multirow[t]{4}{*}{ ED visits (times/year) } & None & $831(88.8)$ & $0.16 \pm 0.66$ & $0-14$ \\
\hline & 1 & $82(8.8)$ & & \\
\hline & 2 & $14(1.5)$ & & \\
\hline & $\geq 3$ & $9(0.9)$ & & \\
\hline \multicolumn{5}{|l|}{ Social characteristics } \\
\hline \multirow[t]{4}{*}{ Participation in social activity } & $\geq 3-4$ times/week & $425(45.4)$ & & \\
\hline & $\geq 1-2$ times/week & $218(23.3)$ & & \\
\hline & $\geq 1-2$ times/month & $43(4.6)$ & & \\
\hline & None & $250(26.7)$ & & \\
\hline \multirow[t]{5}{*}{ Interactions with family members } & $\geq 1-2$ times/week & $438(46.9)$ & & \\
\hline & $\geq 1-2$ times/month & $225(24.0)$ & & \\
\hline & $\geq 1-2$ times/quarter & $75(8.0)$ & & \\
\hline & $\geq 1-2$ times/year & $89(9.5)$ & & \\
\hline & None & $109(11.6)$ & & \\
\hline \multirow[t]{5}{*}{ Interactions with neighbours } & $\geq 1-2$ times/week & $698(74.6)$ & & \\
\hline & $\geq 1-2$ times/month & $97(10.4)$ & & \\
\hline & $\geq 1-2$ times/quarter & $15(1.6)$ & & \\
\hline & $\geq 1-2$ times/year & $19(2.0)$ & & \\
\hline & None & $107(11.4)$ & & \\
\hline \multirow[t]{2}{*}{ Public service utilisation } & Yes & $423(45.2)$ & & \\
\hline & No & $513(54.8)$ & & \\
\hline \multirow[t]{3}{*}{ Social support } & Good & $202(21.6)$ & $3.71 \pm 1.94$ & $0-6$ \\
\hline & Fair & $349(37.3)$ & & \\
\hline & Poor & $385(41.1)$ & & \\
\hline \multirow[t]{4}{*}{ Loneliness } & High & $71(7.6)$ & $41.89 \pm 13.57$ & $20-80$ \\
\hline & Moderately high & $189(20.2)$ & & \\
\hline & Moderate & $342(36.5)$ & & \\
\hline & Low & 334 (35.7) & & \\
\hline
\end{tabular}


Table 3 Self-confidence to live alone by the characteristics of participants ( $N=936)$

\begin{tabular}{|c|c|c|c|}
\hline \multirow[t]{2}{*}{ Variables } & \multirow[t]{2}{*}{ Categories } & \multicolumn{2}{|c|}{ Self-confidence to live alone } \\
\hline & & Mean $\pm S D$ & $t(p)$ \\
\hline \multicolumn{4}{|l|}{ General characteristics } \\
\hline \multirow[t]{2}{*}{ Age (years) } & $65-74$ & $6.78 \pm 2.92$ & $1.363(.173)$ \\
\hline & $\geq 75$ & $6.49 \pm 3.05$ & \\
\hline \multirow[t]{2}{*}{ Sex } & Male & $6.40 \pm 2.91$ & $1.098(.272)$ \\
\hline & Female & $6.65 \pm 3.04$ & \\
\hline \multirow[t]{2}{*}{ Educational level } & $<$ Middle school & $6.44 \pm 3.14$ & $2.360(.019)$ \\
\hline & $\geq$ Middle school & $6.91 \pm 2.69$ & \\
\hline \multirow[t]{2}{*}{ Religion } & Yes & $6.61 \pm 2.95$ & $0.271(.787)$ \\
\hline & No & $6.55 \pm 3.13$ & \\
\hline \multirow[t]{2}{*}{ Participation in economic activity } & $<3-4$ times/week & $6.40 \pm 3.04$ & $3.346(.001)$ \\
\hline & $\geq 3-4$ times/week & $7.15 \pm 2.85$ & \\
\hline \multirow[t]{2}{*}{ Wall cracks at home } & Yes & $6.13 \pm 3.14$ & $2.370(.018)$ \\
\hline & No & $6.71 \pm 2.96$ & \\
\hline \multirow[t]{2}{*}{ Mould exposure at home } & Yes & $5.81 \pm 3.12$ & $5.242(<.001)$ \\
\hline & No & $6.92 \pm 2.90$ & \\
\hline \multicolumn{4}{|l|}{ Health-related characteristics } \\
\hline \multirow[t]{2}{*}{ Disability } & Yes & $6.38 \pm 3.13$ & $1.068(.286)$ \\
\hline & No & $6.64 \pm 2.98$ & \\
\hline \multirow[t]{2}{*}{ IADL } & Independent & $6.89 \pm 2.87$ & $6.618(<.001)$ \\
\hline & Partially or totally dependent & $5.26 \pm 3.23$ & \\
\hline \multirow[t]{2}{*}{ Depression } & No & $7.96 \pm 2.32$ & $14.051(<.001)$ \\
\hline & Yes & $5.50 \pm 3.05$ & \\
\hline \multicolumn{4}{|l|}{ Social characteristics } \\
\hline \multirow[t]{2}{*}{ Participation in social activity } & $<3-4$ times/week & $6.30 \pm 3.03$ & $3.256(.001)$ \\
\hline & $\geq 3-4$ times/week & $6.94 \pm 2.94$ & \\
\hline \multirow[t]{2}{*}{ Interactions with family members } & $<1-2$ times/month & $5.78 \pm 3.14$ & $5.168(<.001)$ \\
\hline & $\geq 1-2$ times/month & $6.92 \pm 2.89$ & \\
\hline \multirow[t]{2}{*}{ Interactions with neighbours } & $<1-2$ times/month & $5.71 \pm 3.49$ & $3.333(.001)$ \\
\hline & $\geq 1-2$ times/month & $6.75 \pm 2.89$ & \\
\hline \multirow[t]{2}{*}{ Public service utilisation } & None & $6.95 \pm 2.82$ & $4.062(<.001)$ \\
\hline & $\geq 1$ & $6.15 \pm 3.17$ & \\
\hline \multirow[t]{2}{*}{ Social support } & Good or Fair & $7.31 \pm 2.58$ & $8.760(<.001)$ \\
\hline & Poor & $5.56 \pm 3.27$ & \\
\hline \multirow[t]{2}{*}{ Loneliness } & $\leq$ Moderate & $7.14 \pm 2.69$ & $8.599(<.001)$ \\
\hline & $\geq$ Moderately high & $5.16 \pm 3.31$ & \\
\hline
\end{tabular}

SD Standard deviation, IADL Instrumental activities of daily living

.046 in Model 1 to .244 in Model 3. The change from Model 1 to Model 2 with health-related characteristics was the largest $\left(\Delta R^{2}=.171\right)$. In the final regression model, mould exposure at home, IADL, depression, history of ED visits, interactions with family members, social service utilisation, social support, and loneliness were selected as predictive factors for self-confidence to live alone.

\section{Discussion}

In the present study, mould exposure at home, IADL, depression, ED visits, interactions with family members, public service utilisation, social support, and loneliness were significant predictive factors for self-confidence in living alone.

The concept of self-confidence to live alone was introduced for the first time to promote successful AIP 
Table 4 Correlations between self-confidence to live alone and other variables ( $N=936)$

\begin{tabular}{llllll}
\hline Variables & Self-confidence to live alone & Age & Personal income & Number of comorbidities & Falls \\
\hline Age (years) & $-.061(.062)$ & & & & \\
Personal income (KRW/month) & $.118(<.001)$ & $-.214(<.001)$ & & & \\
Number of comorbidities & $-.172(<.001)$ & $-.018(.579)$ & $-.063(.053)$ & & \\
Falls (times/year) & $-.112(.001)$ & $.005(.874)$ & $-.032(.326)$ & $.106(.001)$ \\
ED visits (times/year) & $-.141(<.001)$ & $-.026(.418)$ & $-.044(.178)$ & $.094(.004)$ & $.051(.119)$ \\
\hline
\end{tabular}

ED Emergency department, KRW Korean Won

among older adults living alone, and the influencing factors were identified by comprehensively considering the characteristics of ageing. Self-confidence is a familiar and handy indicator that can consider various statuses, coping skills, competence, and knowledge [18]. Therefore, the findings of this study may be evidence that selfconfidence to live alone could be a new practical index in the field of health and ageing to screen for successful AIP among older adults living alone.

The average self-confidence to live alone was 6.59 points, slightly higher than the medium score of 5 . While refraining from drawing hasty conclusions, it is possible to speculate the reasons for the current findings based on a previous study demonstrating that the

Table 5 Factors for self-confidence to live alone $(N=936)$

\begin{tabular}{|c|c|c|c|c|c|c|c|c|c|c|c|c|}
\hline \multirow[t]{2}{*}{ Variables } & \multicolumn{4}{|c|}{ Model 1} & \multicolumn{4}{|c|}{ Model 2} & \multicolumn{4}{|c|}{ Model 3} \\
\hline & $B$ & $S E$ & $B$ & $p$ & $B$ & $S E$ & B & $p$ & $B$ & $S E$ & B & $p$ \\
\hline Constant & 4.097 & .495 & & $<.001$ & 6.778 & .507 & & $<.001$ & 6.502 & .616 & & $<.001$ \\
\hline \multicolumn{13}{|l|}{ General characteristics } \\
\hline Educational level (ref. < middle school) & 0.252 & .213 & .039 & .237 & 0.075 & .197 & .012 & .380 & 0.082 & .196 & .013 & .677 \\
\hline Personal income (KRW/month) & $\begin{array}{l}6.122 \mathrm{E}- \\
7\end{array}$ & $\begin{array}{l}< \\
.001\end{array}$ & .081 & .016 & $\begin{array}{l}3.056 \mathrm{E}- \\
7\end{array}$ & $\begin{array}{l}< \\
.001\end{array}$ & .040 & .188 & $\begin{array}{l}2.398 \mathrm{E}- \\
7\end{array}$ & $\begin{array}{l}< \\
.001\end{array}$ & .032 & .294 \\
\hline $\begin{array}{l}\text { Participation in economic activity (ref. }<3-4 \text { times/ } \\
\text { week) }\end{array}$ & 0.656 & .225 & .095 & .004 & 0.483 & .207 & .070 & .020 & 0.379 & .204 & .055 & .064 \\
\hline Wall cracks at home (ref. yes) & 0.023 & .263 & -.003 & .929 & -0.081 & .239 & -.011 & .736 & 0.005 & .236 & .001 & .983 \\
\hline Mould exposure at home (ref. yes) & 1.074 & .231 & -.163 & $\begin{array}{l}< \\
.001\end{array}$ & 0.746 & .212 & .113 & $\begin{array}{l}< \\
.001\end{array}$ & 0.686 & .209 & .104 & .001 \\
\hline \multicolumn{13}{|l|}{ Health-related characteristics } \\
\hline IADL (ref. Independent) & & & & & -0.981 & .235 & -.127 & $\begin{array}{l}< \\
.001\end{array}$ & -0.872 & .233 & -.113 & $\begin{array}{l}< \\
.001\end{array}$ \\
\hline Number of comorbidities & & & & & -0.048 & .039 & -.038 & .215 & -0.043 & .038 & -.034 & .264 \\
\hline Depression (ref. normal) & & & & & -2.056 & .186 & -.340 & $\begin{array}{l}< \\
.001\end{array}$ & -1.579 & .199 & -.261 & $\begin{array}{l}< \\
.001\end{array}$ \\
\hline Falls (times/year) & & & & & -0.128 & .063 & -.060 & .041 & -0.100 & .062 & -.047 & .107 \\
\hline ED visit (times/year) & & & & & -0.388 & .135 & -.085 & .004 & -0.359 & .133 & -.079 & .007 \\
\hline \multicolumn{13}{|l|}{ Social characteristics } \\
\hline Participation in social activity (ref. $<3-4$ times/week) & & & & & & & & & 0.192 & .181 & .032 & .290 \\
\hline Interactions with family members (ref. $<1-2$ times/m & nonth) & & & & & & & & 0.453 & .203 & .068 & .026 \\
\hline Interactions with neighbours (ref. $<1-2$ times/month & & & & & & & & & -0.282 & .277 & -.034 & .308 \\
\hline Public service utilisation (ref. $\geq 1$ ) & & & & & & & & & 0.415 & .178 & .069 & .020 \\
\hline Social support (ref. Good or Fair) & & & & & & & & & -0.659 & .206 & -.108 & .001 \\
\hline Loneliness (ref. $\leq$ Moderate) & & & & & & & & & -0.590 & .244 & -.088 & .016 \\
\hline$R^{2}\left(\Delta R^{2}\right)$ & \multicolumn{4}{|c|}{$.051(.051)$} & \multicolumn{4}{|c|}{$.222(.171)$} & \multicolumn{4}{|c|}{$.257(.035)$} \\
\hline Adjusted $R^{2}$ & \multicolumn{4}{|l|}{.046} & \multicolumn{4}{|l|}{.213} & \multicolumn{4}{|l|}{.244} \\
\hline$\Delta F(p)$ & \multicolumn{4}{|c|}{$9.937(<.001)$} & \multicolumn{4}{|c|}{$26.347(<.001)$} & \multicolumn{4}{|c|}{$19.869(<.001)$} \\
\hline
\end{tabular}

SE Standard error, IADL Instrumental activities of daily living, ED Emergency department, KRW Korean Won 
proportion of vulnerable groups who responded as 'very confident to live in place' was higher than that of the non-vulnerable group [45]. Older adults living alone are a relatively vulnerable residential group among all older adults. According to a prospective study, although baseline states of mental health and physical function were lower in older women living alone than in those who live with a spouse, older women living alone were not at risk for declining in functional status longitudinally [46]. It can be assumed that as older adults living alone try to adapt and balance changes by themselves (e.g. functional, social, and environmental changes), they might be able to perceive their potential power affirming control over their own life, which is more important than actualising it for successful AIP [16].

Interaction with family members, public service utilisation, social support, and loneliness were predictive factors in the aspect of social characteristics. Participants in the current study were more isolated from family members than those in a previous study conducted in the United States (mean age $=67$ years). The results originated from the properties of single living. Nevertheless, it has several implications in terms of familial interactions being an important factor to instil confidence to live alone among these older adults. First, consistent with a previous study [21], it was identified that family is still an essential social network for healthy AIP, despite older adults living alone being significantly more isolated from family than those living with others [3]. This finding strengthens the importance of familial networks for older adults living alone.

Similarly, a second implication is the health providers' and policy makers' need to pay attention to familial networks for solitary living older adults to promote social networks. Despite the importance of familial connectedness, according to a previous study that reviewed interventions for social connectedness, many studies have focussed on improving contacts with groups or individuals rather than with family members (e.g. peer-group support or community-based programmes) [47]. Research evidence shows that technology-assisted interventions improve social connectedness and belongingness [48], and technological strategies are helpful in promoting familial networks for older adults living alone.

Interestingly, those who use public services showed lower self-confidence to live alone in the current study. Contrary to our results, a generous utilisation of welfare and public services was positively associated with both living alone and actualisation of AIP $[6,25]$. This difference could be due to shortcomings in the quantity and quality of services, as inferred from previous studies. Solitary living older adults stated the need for public services to live independently [19] but mentioned limited time [19] and provider-oriented services as disadvantages [49].

In addition, this study shows that social support is an important factor in instilling self-confidence for living alone. This can be linked to the results of existing studies that show social support as essential to maintain independent AIP among older adults living alone. In previous qualitative studies, older adults living alone emphasised that informal social supports were crucial sources of emotional as well as instrumental support such as meal preparation, housework, and hospital visits $[17,19]$. In particular, these individuals had significantly lower social support and daily housework support when they were sick than those living with others [50]. Therefore, strengthening a community-based social support system can improve self-confidence to live alone and further enhance independent living for older adults living alone. However, one limitation of this cross-sectional research is that this association must be further explored in prospective studies. The negative relationship between loneliness and self-confidence to live alone found in this study is consistent with a previous study that revealed a negative correlation between loneliness and self-esteem mediated by positive coping strategies [51]. In particular, according to a previous study, older adults living alone experienced more emotional loneliness than those living with others [3]. Therefore, reducing the emotional loneliness of older adults living alone and improving strategies for positive coping skills can increase confidence in living alone and can lead to successful AIP.

With respect to health-related factors, IADL and depression were important for self-confidence to live alone as demonstrated in many studies. IADL and depression are factors that share several important aspects of independent living for older adults. According to a previous study on these individuals, the declining capability of IADL increases their difficulties in daily living, such as household affairs, shopping, gardening, and household maintenance, which makes it harder for them to live independently and increases feelings of depression [52, 53]. In other aspects, difficulties in IADL hinder social activities, making older adults depressed, and eventually impairing their sense of mastery over their own life [54]. Therefore, for older adults to live independently, it is necessary to examine those who have difficulties with IADL, to identify domains requiring support in the IADL, and to establish an easily accessible social daily living assistance system. In addition, in-depth evaluation of the causes of depression is required for the elderly living alone with low confidence in AIP, and tailored interventions based on that can lead to successful AIP.

History of ED visits was a significant factor in lowering self-confidence to live alone. Most older adults living alone require emergency support services, especially for 
safety [55]. This means that people living alone must confront and handle any life-threatening situation without immediate help, which may make them anxious. This experience of helplessness in a life crisis situation can negatively affect self-confidence in living alone and can even lead to dependency upon others. Therefore, reducing the incidence of emergency situations among older adults living alone could increase their selfconfidence to live alone.

Finally, exposure to indoor microbial pollutants is a well-known health hazard that causes many symptoms and diseases [23]. It can be assumed that long-term exposure to such an adverse environment leads to chronic pain and decline in health, resulting in poor quality of life and, consequently, reducing the confidence to live alone. Therefore, periodic inspection of the residential conditions of older adults living alone is necessary, alongside health education on the importance of home management methods.

Despite these findings, the current study has some limitations. First, since this study was the first to measure the confidence to live alone, the concept was defined as evidenced in previous studies related to AIP, independent living, and healthy and successful ageing. For a more consistent implementation of the concept in the field, further conceptual analysis is necessary. Second, self-confidence to live alone was measured using a simple and convenient NRS scale considering the characteristics of older adults, however, it is not a structured tool. Thus, future studies need to develop a standardised measurement and present clinimetric properties. Third, this study comprehensively encompasses many variables based on previous studies, but there were limits to exploring related factors in-depth due to secondary data analysis. Further research needs to explore factors with their constituent domains and their pathways. Fourth, though the original data were collected by trained assistants, interpretation of the results should be done with caution as this study could potentially be impacted by self-report bias.

\section{Conclusions}

Self-confidence to live alone-a new and practical indicator for screening successful AIP among older adults living alone-was slightly higher than the mean value of the scale. To increase self-confidence to live alone, intervention measures must focus on improving interactions with family members, public service utilisation, social support, loneliness, IADL, depression, ED visits, and mould exposure at home. The findings have scope for fostering independent living and successful AIP among older adults living alone.

\section{Abbreviations}

AIP: Ageing in place; ED: Emergency Department; ENRICHD: Enhancing recovery in coronary health disease; ESSI: ENRICHD social support instrument; K-IADL: Korean instrumental activities of daily living; KRW: Korean Won; MMSE: Mini-mental status examination; NRS: Numeric rating scale;

SD: Standard deviation; SE: Standard error; VIF: Variance inflation factor

\section{Acknowledgements}

Not applicable.

\section{Authors' contributions}

Y.H. and B.L. planned the study, supervised the data analysis, and S.I. wrote the paper. Y.H. and S.I. contributed to revising the paper. S.J. and H.N. helped to plan the study, including the instrumentation. Y.M., E.Y., and H.R. participated in data collection and data analysis. All authors read and approved the final manuscript.

\section{Funding}

This work was supported by a grant from the Korea Health Technology R\&D Project through the Korea Health Industry Development Institute (KHDI), funded by the Ministry of Health \& Welfare, Republic of Korea (grant number: HI18C1284).

\section{Availability of data and materials}

The data used and/or analysed during the current study are available from the corresponding author on reasonable request.

\section{Declarations}

\section{Ethics approval and consent to participate}

The original study was performed with the approval of the Institutional Review Board (IRB) at Seoul National University Hospital (approval no. $\mathrm{H}$ 1807-131-961). All participants provided written informed consent prior to participation and were informed that they could withdraw their consent at any time without any disadvantage. For the current secondary data analysis, data were received from the principle investigator of the original study after obtaining approval from the IRB at the Seoul National University (approval no. E2011/001-003). All methods were performed in accordance with the relevant guidelines and regulations.

\section{Consent for publication}

Not applicable.

\section{Competing interests}

The authors declare that they have no competing interests.

\section{Author details}

${ }^{1}$ College of Nursing, The Research Institute of Nursing Science, Seoul National University, Seoul, 103, Daehak-ro, Jongno-gu, Seoul 03080, Republic of Korea. ${ }^{2}$ Department of Family Medicine, College of Medicine, Seoul National University, Seoul, 103, Daehak-ro, Jongno-gu, Seoul 03080, Republic of Korea. ${ }^{3}$ Institute on Aging, Seoul National University College of Medicine, 71 Ihwajang-Gil, Jongno-gu, Seoul 110-810, Republic of Korea. ${ }^{4}$ College of Nursing, Seoul National University, Seoul, 103, Daehak-ro, Jongno-gu, Seoul 03080, Republic of Korea. ${ }^{5}$ College of Nursing, Gachon University, 191 Hambakmoero, Yeonsu-gu, Incheon 21936, Republic of Korea. ${ }^{6}$ College of Nursing, Kyungnam College of Information and Technology, 45 Jurye-ro, Sasang-gu, Busan 47011, Republic of Korea.

Received: 16 November 2020 Accepted: 7 April 2021

Published online: 04 May 2021

\section{References}

1. Reher D, Requena M. Living alone in later life: a global perspective. Popul Dev Rev. 2018;44(3):427-54. https://doi.org/10.1111/padr.12149.

2. Statistics Korea. Population projection for Korea. 2019. https://kosis.kr/sta tHtml/statHtml.do?orgld=101\&tblld=DT_1BZ0503\&vw_cd=MT_ZTITLE\&list_ $\mathrm{id}=\mathrm{A} 42 \_10 \&$ segNo=\&lang_mode $=$ ko\&language $=$ kor\&obj_var_id=\&itm_id $=$ \&conn_path=MT_ZTITLE. Accessed 10 October 2020. 
3. Evans IEM, Llewellyn DJ, Matthews FE, Woods RT, Brayne C, Clare L, et al. Living alone and cognitive function in later life. Arch Gerontol Geriatr. 2019; 81:222-33. https://doi.org/10.1016/j.archger.2018.12.014.

4. Roh M, Weon S. Living arrangement and life satisfaction of the elderly in South Korea. Soc Indic Res [Internet]. 2020. https://doi.org/10.1007/s11205020-02443-3. Accessed 10 October 2020.

5. Srugo SA, Jiang Y, de Groh M. At-a-glance - Living arrangements and health status of seniors in the 2018 Canadian Community Health Survey. Health Promot Chronic Dis Prev Can. 2020;40(1):18-22. https://doi.org/10.24095/ hpcdp.40.1.03

6. Kendig H, Gong CH, Cannon L, Browning C. Preferences and predictors of aging in place: longitudinal evidence from Melbourne. Australia. J Hous Elderly. 2017;31(3):259-71. https://doi.org/10.1080/02763893.2017.1280582.

7. Korea Institute for Health and Social Affairs. 2017 survey of living conditions and welfare needs of Korean older persons. 2018. https://www.kihasa.re.kr/ web/publication/research/view.do?menuld=45\&tid=71\&bid=12\&division= 002\&ano=2298. Accessed 10 October 2020.

8. Bigonnesse C, Chaudhury H. The landscape of "aging in place" in gerontology literature: emergence, theoretical perspectives, and influencing factors. J Aging Environ. 2020;34(3):233-51. https://doi.org/10.1080/02763 893.2019.1638875.

9. WHO Centre for Health Development (Kobe, Japan). A glossary of terms for community health care and services for older persons. Kobe: WHO Centre for Health Development; 2004. https://apps.who.int/iris/handle/10665/68896. Accessed 10 October 2020

10. Ahn M. Introduction to special issue: aging in place. Hous Soc. 2017:44(1-2): 1-3. https://doi.org/10.1080/08882746.2017.1398450.

11. Stones D, Gullifer J. 'At home it's just so much easier to be yourself': older adults' perceptions of ageing in place. Ageing Soc. 2016;36(3):449-81. https://doi.org/10.1017/s0144686×14001214.

12. Torres-Gil F, Hofland B. Vulnerable populations. In H. Cisneros, M. DyerChamberlain, \& J. Hickies (Eds.), Independent for life: Homes and neighborhoods for an aging America. Austin: University of Texas Press; 2012. p. 221-32.

13. Hillcoat-Nallétamby S. The meaning of "independence" for older people in different residential settings. J Gerontol B Psychol Sci Soc Sci. 2014;69(3): 419-430. https://doi.org/10.1093/geronb/gbu008

14. Mirowsky J. Age and the sense of control. Soc Psychol Q. 1995;58(1):31. https://doi.org/10.2307/2787141.

15. Lawton MP. The elderly in context: perspectives from environmental psychology and gerontology. Environ Behav. 1985;17(4):501-19. https://doi. org/10.1177/0013916585174005.

16. Pirhonen J, Pietilä I. Perceived resident-facility fit and sense of control in assisted living. J Aging Stud. 2016;38:47-56. https://doi.org/10.1016/j.jaging.2 016.04.006.

17. Dupuis-Blanchard S, Gould ON, Gibbons C, Simard M, Éthier S, Villalon L. Strategies for aging in place: the experience of language-minority seniors with loss of independence. Glob Qual Nurs Res. 2015;(2):1-9. https://doi. org/10.1177/2333393614565187.

18. Moore BM. Self-confidence for competence. Edu Leader. 1952;12:140-5.

19. Narushima M, Kawabata M. "Fiercely independent": experiences of aging in the right place of older women living alone with physical limitations. J Aging Stud. 2020;54:100875. https://doi.org/10.1016/j.jaging.2020.100875.

20. Bacsu J, Jeffery B, Abonyi S, Johnson S, Novik N, Martz D, et al. Healthy aging in place: perceptions of rural older adults. Educ Gerontol. 2014;40(5): 327-37. https://doi.org/10.1080/03601277.2013.802191.

21. Li B, Chen S. A study of residential condition and satisfaction of the elderly in China. J Hous Elderly. 2011;25(1):72-88. https://doi.org/10.1080/02763 893.2011.545746.

22. World Health Organization Regional Office for Europe. WHO guidelines for indoor air quality: dampness and mould [Internet]. 2009. https://www.euro. who.int/_data/assets/pdf_file/0017/43325/E92645.pdf. Accessed 10 October 2020

23. Fernández-Carro C, Módenes JA, Spijker J. Living conditions as predictor of elderly residential satisfaction. A cross-European view by poverty status. Eur J Ageing. 2015;12(3):187-202. https://doi.org/10.1007/s10433-015-0338-z.

24. Lee YS, Kim YS, Sung CH, Shin YJ, Cho WS. A descriptive research on field situation of customized modification for vulnerable single elderly home. J Korean Hous Assoc. 2017;28(3):55-64. https://doi.org/10.6107/jkha.2017.28.3.055.

25. Mudrazija S, Angel J, Cipin I, Smolic S. Living alone in the United States and Europe: the impact of public support on the independence of older adults.
Innov Aging. 2018;2(suppl_1):769-70. https://doi.org/10.1093/geroni/ igy023.2849.

26. Park S, Han Y, Kim B, Dunkle RE. Aging in place of vulnerable older adults: person-environment fit perspective. J Appl Gerontol. 2017;36(11):1327-50. https://doi.org/10.1177/0733464815617286.

27. Falls. World Health Organization. 2018. https://www.who.int/news-room/fa ct-sheets/detail/falls. Accessed 10 October 2020.

28. Choi NG, Choi BY, DiNitto DM, Marti CN, Kunik ME. Fall-related emergency department visits and hospitalizations among community-dwelling older adults: examination of health problems and injury characteristics. BMC Geriatr. 2019;19(1):303. https://doi.org/10.1186/s12877-019-1329-2.

29. Dingová M, Králová E. Fear of falling among community dwelling older adults. Cent Eur J Nurs Midwifery. 2017;8(1):580-7. https://doi.org/10.15452/ cejnm.2017.08.0005

30. Lau DT, Scandrett KG, Jarzebowski M, Holman K, Emanuel L. Health-related safety: a framework to address barriers to aging in place. Gerontologist. 2007:47(6):830-7. https://doi.org/10.1093/geront/47.6.830.

31. Care service for older adults. Ministry of Health Welfare. 2017. https://www. mohw.go.kr/react/jb/sjb030301vw.jsp.PAR_MENU_ID=03\&MENU_ID=032901 \&CONT_SEQ=338646. Accessed 10 Oct 2020.

32. Won CW, Yang KY, Rho YG, Kim SY, Lee EJ, Yoon JL, et al. The development of Korean activities of daily living (K-ADL) and Korean instrumental activities of daily living (K-IADL) scale. J Korean Geriatr Soc. 2002; 6(2): 107-120. https://www.e-agmr.org/journal/view.php?number=280. Accessed 10 October 2020.

33. Lee HS, Kim HS, Jung YM. Depression and quality of life in Korean elders. J Korean Acad Commun Health Nurs. 2009;20(1):12-22. https://www.korea science.or.kr/article/JAKO200916263468652.pdf. Accessed 7 Mar 2021.

34. Won CW, Rho YG, Sunwoo D, Lee YS. The validity and reliability of Korean Instrumental Activities of Daily Living (K-IADL) scale. J Korean Geriatr Soc. 2002; 6(4): 273-280. https://www.e-agmr.org/journal/view.php?vol=6\&issue= 4\&spage $=273$. Accessed 7 March 2021.

35. Kee BS. A preliminary study for the standardization of geriatric depression scale short form-Korea version. J Korean Neuropsychiatr Assoc. 1996; 35(2): 298-307. https://kmbase.medric.or.kr/Main.aspx?menu=01\&d=KMBASE\&m= VIEW\&i=0368819960350020298. Accessed 10 Oct 2020.

36. Sheikh JI, Yesavage JA. Geriatric depression scale (GDS): recent evidence and development of a shorter version. Clin Gerontol. 1986;5(1-2):165-73. https://doi.org/10.1300/J018v05n01_09.

37. Mortimer JA, Ding D, Borenstein AR, DeCarli C, Guo Q, Wu Y, et al. Changes in brain volume and cognition in a randomized trial of exercise and social interaction in a community-based sample of non-demented Chinese elders. J Alzheimers Dis. 2012;30(4):757-66. https://doi.org/10.3233/JAD-2012-120079.

38. Shankar A, McMunn A, Banks J, Steptoe A. Loneliness, social isolation, and behavioral and biological health indicators in older adults. Health Psychol. 2011;30(4):377-85. https://doi.org/10.1037/a0022826.

39. Mitchell PH, Powell L, Blumenthal J, Norten J, Ironson G, Pitula CR, et al. A short social support measure for patients recovering from myocardial infarction: the enriched social support inventory. J Cardiopulm Rehabil. 2003;23(6):398-403. https://doi.org/10.1097/00008483-200311000-00001.

40. Jeon GS, Jang SN, Park S. Social support, social network, and frailty in Korean elderly. J Korean Geriatr Soc. 2012;16(2):84-94. https://doi.org/10.423 5/jkgs.2012.16.2.84.

41. Kim OS. Korean version of the revised UCLA loneliness scale: reliability and validity test. Kanho Hakhoe Chi. 1997;27(4):871-9. https://doi.org/10.4040/jna s.1997.27.4.871.

42. Russell D, Peplau LA, Cutrona CE. The revised UCLA Loneliness Scale: concurrent and discriminant validity evidence. J Pers Soc Psychol. 1980; 39(3):472-80. https://doi.org/10.1037/0022-3514.39.3.472.

43. Perry GR. Loneliness and coping among tertiary-level adult cancer patients in the home. Cancer Nurs. 1990;13(5):293-302.

44. Lee IH. Easyflow regression analysis. Seoul: Hannarae; 2016. p. 313-6.

45. Tang F, Lee Y. Home- and community-based services utilization and aging in place. Home Health Care Serv Q. 2010;29(3):138-54. https://doi.org/10.1 080/01621424.2010.511518.

46. Michael YL, Berkman LF, Colditz GA, Kawachi I. Living arrangements, social integration, and change in functional health status. Am J Epidemiol. 2001; 153(2):123-31. https://doi.org/10.1093/aje/153.2.123.

47. O'Rourke HM, Collins L, Sidani S. Interventions to address social connectedness and loneliness for older adults: a scoping review. BMC Geriatr. 2018;18(1):214. https://doi.org/10.1186/s12877-018-0897-x. 
48. Stojanovic J, Collamati A, Duplaga M, Onder G, La Milia DI, Ricciardi W, et al. Decreasing loneliness and social isolation among the older people: systematic search and narrative review. Epidemiol Biostat Public Health. 2017;14(suppl 1):2. https://doi.org/10.2427/12408.

49. Park YH, Lim KC, Cho BL, Ko H, Yi YM, Noh EY, et al. Experiences of healthcare and daily life support services in community-dwelling elders living alone: a thematic analysis using focus group interviewing. J Korean Gerontol Nurs. 2019;21(3):200-10. https://doi.org/10.17079/jkgn.2019.21.3.200.

50. Chan E, Procter-Gray E, Churchill L, Cheng J, Siden R, et al. Associations among living alone, social support and social activity in older adults. AIMS Public Health. 2020;7(3):521-34. https:/doi.org/10.3934/publichealth.2020042.

51. Zhao L, Zhang X, Ran G. Positive coping style as a mediator between older adults' self-esteem and loneliness. Soc Behav Pers. 2017;45(10):1619-28. https://doi.org/10.2224/sbp.6486.

52. Ahlqvist A, Nyfors $\mathrm{H}$, Suhonen R. Factors associated with older people's independent living from the viewpoint of health and functional capacity: a register-based study. Nurs Open. 2016;3(2):79-89. https://doi.org/10.1002/nop2.39.

53. Stahl ST, Beach SR, Musa D, Schulz R. Living alone and depression: the modifying role of the perceived neighborhood environment. Aging Ment Health. 2017;21(10):1065-71. https://doi.org/10.1080/13607863.2016.1191060.

54. Lin IF, Wu HS. Does informal care attenuate the cycle of ADL/IADL disability and depressive symptoms in late life? J Gerontol B Psychol Sci Soc Sci. 2011; 66(5):585-94. https://doi.org/10.1093/geronb/gbr060.

55. Ko H, Park YH, Cho B, Lim KC, Chang SJ, Yi YM, et al. Gender differences in health status, quality of life, and community service needs of older adults living alone. Arch Gerontol Geriatr. 2019;83:239-45. https://doi.org/10.1016/ j.archger.2019.05.009.

\section{Publisher's Note}

Springer Nature remains neutral with regard to jurisdictional claims in published maps and institutional affiliations.

Ready to submit your research? Choose BMC and benefit from:

- fast, convenient online submission

- thorough peer review by experienced researchers in your field

- rapid publication on acceptance

- support for research data, including large and complex data types

- gold Open Access which fosters wider collaboration and increased citations

- maximum visibility for your research: over $100 \mathrm{M}$ website views per year

At $\mathrm{BMC}$, research is always in progress.

Learn more biomedcentral.com/submissions 